\title{
Effects of pleural effusion on respiratory function
}

\author{
I Mitrouska MD, M Klimathianaki MD, NM Siafakas MD PhD
}

I Mitrouska, M Klimathianaki, NM Siafakas. Effects of pleural effusion on respiratory function. Can Respir J 2004;11(7):499-503.

The accumulation of pleural effusion has important effects on respiratory system function. It changes the elastic equilibrium volumes of the lung and chest wall, resulting in a restrictive ventilatory effect, chest wall expansion and reduced efficiency of the inspiratory muscles. The magnitude of these alterations depends on the pleural fluid volume and the underlying disease of the respiratory system. The decrease in lung volume is associated with hypoxemia mainly due to an increase in right to left shunt. The drainage of pleural fluid results in an increase in lung volume that is considerably less than the amount of aspirated fluid, while hypoxemia is not readily reversible upon fluid aspiration.

Key Words: Gas exchange; Lung mechanics; Physiology; Respiratory muscles

\section{Effets de l'épanchement pleural sur la respiration}

L'accumulation de liquide pleural a d'importantes répercussions sur le fonctionnement de l'appareil respiratoire. Elle modifie les volumes d'équilibre élastique des poumons et de la cage thoracique, ce qui entraîne une restriction de la ventilation, une expansion de la cage thoracique et une diminution de l'efficacité des muscles inspiratoires. L'importance de ces changements dépend de la quantité de liquide pleural et de la maladie sous-jacente de l'appareil respiratoire. La diminution du volume des poumons est associée à de l'hypoxémie en raison principalement d'une augmentation du shunt droite-gauche. Le drainage de l'épanchement pleural permet certes une augmentation du volume des poumons, mais celle-ci est beaucoup plus faible que la quantité de liquide aspiré, et l'hypoxémie ne se montre pas vraiment réversible à l'aspiration.
The pleural space is normally a virtual space, $10 \mu \mathrm{m}$ to $20 \mu \mathrm{m}$ 1 wide, that encompasses the area between the mesothelium of the parietal and visceral pleura and contains a small amount of lubricating fluid $(0.3 \mathrm{~mL} / \mathrm{kg}$ body mass $)$ with a low concentration of protein (approximately $1 \mathrm{~g} / \mathrm{dL}$ ) (1). At the functional residual capacity (FRC), there is normally a balance between the inward recoil of the lung and outward recoil of the chest wall, with a concurrent negative pleural pressure.

The pressures of the pleural space are determined by the mechanical properties of the lung and chest wall and, thus, the whole respiratory system (2). The distending pressures of the lung and chest wall are critically dependent on the relevant pressure of the pleural space (3).

The pleural surface pressure (4) usually differs from the pleural liquid pressure due to the presence of contacts between the lung and chest wall, and the additional resulting distortions (4-6). In humans in the upright position, the vertical gradient of pleural surface pressure is approximately $0.25 \mathrm{~cm} \mathrm{H}_{2} \mathrm{O} / \mathrm{cm}$ height, whereas within the liquid column the gradient is somewhat greater (approximately $1 \mathrm{~cm} \mathrm{H} \mathrm{H}_{2} \mathrm{O} / \mathrm{cm}$ height) (7). In healthy humans, the difference between the surface and liquid pleural pressure is relatively small at the bottom of the lung and increases towards the top of the lung, with the liquid pressure becoming more negative than surface pressure.

Visceral pleural pressure influences lung expansion, while parietal pleural pressure affects chest volume. Although the two pressures may be slightly different, for the purposes of the present review, they will be considered equivalent and equal to pleural pressure $\left(\mathrm{P}_{\mathrm{pl}}\right)(5)$.

$\mathrm{P}_{\mathrm{pl}}$, together with alveolar pressure $\left(\mathrm{P}_{\mathrm{alv}}\right)$, sets the transpulmonary $\left(\mathrm{P}_{\mathrm{L}}\right)$ or distending pressure of the lung (8):

$$
\mathrm{P}_{\mathrm{L}}=\mathrm{P}_{\mathrm{alv}}-\mathrm{P}_{\mathrm{pl}}[1]
$$

and at zero flow condition $\left(\mathrm{P}_{\mathrm{alv}}=0\right)$ :

$$
\mathrm{P}_{\mathrm{L}}=-\mathrm{P}_{\mathrm{pl}}[2] \text {. }
$$

Similarly, $\mathrm{P}_{\mathrm{pl}}$ sets the transthoracic $\left(\mathrm{P}_{\mathrm{w}}\right)$ or distending pressure of the chest wall:

$$
\mathrm{P}_{\mathrm{w}}=\mathrm{P}_{\mathrm{pl}}-\mathrm{P}_{\mathrm{bs}}[3] \text {. }
$$

$\mathrm{P}_{\mathrm{bs}}$ is the body surface pressure which is considered to be zero (atmospheric).

The interpretation of the effects of pleural effusion on the respiratory system is rather complicated for several reasons. First, it is difficult to study patients with 'pure' pleural effusion without lung disease. Second, the validity of the esophageal pressure measurement as an approximation of pleural pressure is questionable in patients with pleural effusion $(9,10)$. Finally, data from animal models of pleural effusion may not be applicable in humans because of species differences in pleural anatomy (11).

The effects of pleural effusion on respiratory system function have been the subject of many studies which have shown that pleural effusion has important effects on static respiratory system mechanics (12-14), because it changes the elastic equilibrium volumes of the lung and chest wall. It also affects the dynamic properties of the respiratory system (dynamic elastance and resistance); function of respiratory muscles; gas exchange within the lung; and heart-lung interaction.

\section{RESPIRATORY SYSTEM MECHANICS}

An increase in the amount of fluid in the pleural space causes an increase in pleural pressure, which results in an alteration of the 


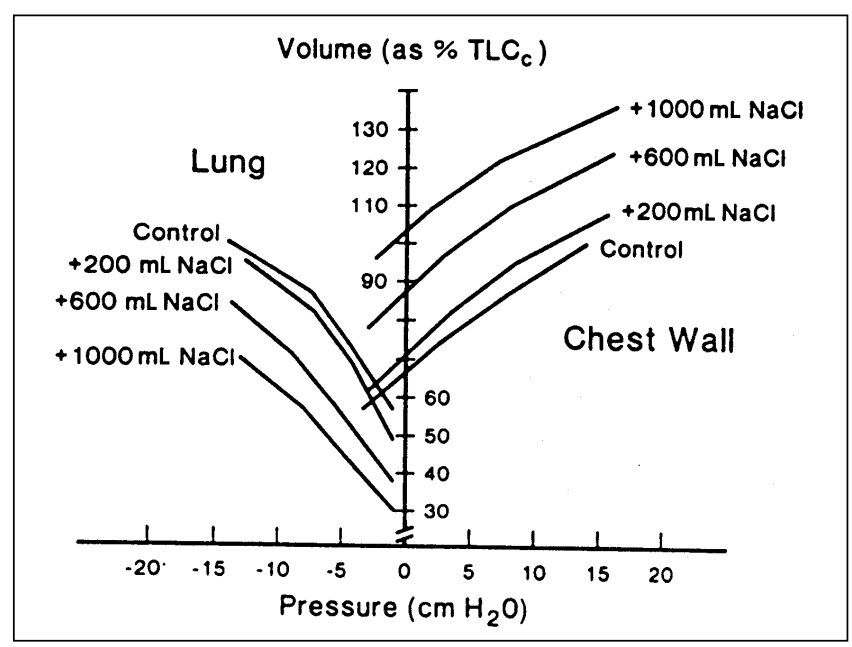

Figure 1) Pressure-volume curves for the lung and chest wall in the control state and after each of three saline $(\mathrm{NaCl})$ additions (labelled for each saline volume). Volume is expressed as percentage of control total lung capacity (TLC $C_{c}$ ) and represents lung (left) and chest wall (right) volume with and without (control) saline. Pressure in $\mathrm{cm}_{2} \mathrm{O}$ is esophageal pressure minus airway opening pressure for lungs, and esophageal pressure minus atmospheric pressure (considered to be zero) for the chest wall. Reproduced with permission from reference 14

distending pressure of chest wall $\left(\Delta \mathrm{P}_{\mathrm{pl}}\right)$ and lung $\left(\Delta \mathrm{P}_{\mathrm{L}}\right)$. Accordingly, assuming that the compliance of the chest wall $\left(\mathrm{C}_{\mathrm{w}}\right)$ and lung $\left(\mathrm{C}_{\mathrm{L}}\right)$ remain unchanged, the volume of the chest wall $\left(\Delta \mathrm{V}_{\mathrm{w}}\right)$ increases and the volume of the lung $\left(\Delta \mathrm{V}_{\mathrm{L}}\right)$ decreases (12), as dictated by the following equations:

$$
\Delta \mathrm{V}_{\mathrm{w}}=\mathrm{C}_{\mathrm{w}} \Delta \mathrm{P}_{\mathrm{pl}}[4]
$$

$$
\text { and } \Delta \mathrm{V}_{\mathrm{L}}=\mathrm{C}_{\mathrm{L}} \Delta \mathrm{P}_{\mathrm{L}}\left(\Delta \mathrm{V}_{\mathrm{L}}=\mathrm{C}_{\mathrm{L}} \Delta \mathrm{P}_{\mathrm{pl}}\right. \text { at zero flow) [5]. }
$$

It follows that with pleural effusion an uncoupling between the volume of lung and chest wall occurs; the volume of the chest wall is no longer equal to that of the lung, a situation which is, to some extent, similar to that encountered in pneumothorax. The differences between these two conditions are mainly due to the enhanced gravitational gradient of pleural pressure due to the presence of liquid and to the fact that pleural effusion does not usually occupy the whole pleural space but creates local alterations in pleural pressure.

Based on theoretical considerations, pleural effusion should cause a restrictive ventilatory defect characterized by a reduction in vital capacity (VC), FRC and total lung capacity (TLC). Although the above analysis is oversimplified because it does not take into account possible secondary effects of pleural effusion on the pressure-volume curve of the chest wall and lung, and the interaction between the two hemithoraces, it provides a useful framework to explain the effects of pleural effusion on respiratory function.

The effect of pleural effusion on respiratory system mechanics may be studied experimentally either by instillation of fluid into the pleural space or by removal of fluid from the pleural space. Obviously, the first method is used in animals (13-15), while in humans $(16-20)$, the second is the only practical method to study the effects of pleural effusion.

Animal data indicate that the addition of fluid into the pleural space causes a concurrent increase in chest wall volume and decrease in lung volume, confirming the theoretical predictions. In head-up dogs, Krell and Rodarte (14) showed that lung volume decreased by approximately one-third of the added saline volume at the FRC and by one-fifth at TLC. On the other hand, the chest wall volume increased by two-thirds of the instilled volume at the FRC and by four-fifths at TLC. The pressure-volume curves showed an apparent increase in lung elastic recoil and a decrease in chest wall elastic recoil with the addition of saline (Figure 1). The authors further showed that the reduction in lung volume was mainly due to a reduction in lower lobe volume with minimal change in upper lobe volume. This implied there was an increase of the vertical gradient of regional lung volumes with increasing effusion volumes. These results indicate that pleural effusion produces a nonuniform alteration in pleural pressure, which, in turn, affects the regional lung and chest wall volumes.

The static changes induced by pleural effusion may also alter the dynamic properties of respiratory system. Dechman et al (13) infused normal saline into the pleural space of dogs and calculated the dynamic elastance and resistance of the respiratory system, lung and chest wall. Pleural effusion caused a marked increase in respiratory system elastance (decreased compliance) and resistance due to an alteration in the dynamic properties of the lung, while it decreased dynamic elastance (increased compliance) and resistance of the chest wall. Sousa et al (15) observed that pleural effusion increased the respiratory system and lung elastances in rats, while the resistances remained relatively constant. The changes in the dynamic properties of the lung were partially reversed by deep inflation, suggesting that airway closure may be an important determinant of these alterations (13). These secondary effects of pleural effusion on lung function should be considered when therapy is planned in patients.

The effects of pleural effusion on respiratory system function have also been examined in humans in several studies (1618,21). However, the interpretation of the results is difficult, mainly due to underlying lung diseases. Indeed, it has been found that pleural effusion is not always associated with an increase in pleural pressure. Light et al (22) directly measured pleural pressure in a large number of patients with pleural effusion and observed values between $-21 \mathrm{~cm} \mathrm{H}_{2} \mathrm{O}$ to $+8 \mathrm{~cm} \mathrm{H}_{2} \mathrm{O}$. In a subsequent study (19), the same group showed that the increase in $\mathrm{VC}$, as a result of removing an amount of pleural fluid, was related both to the initial value of pleural pressure and with its change during aspiration. A markedly negative initial pressure or a large change during aspiration was associated with a relatively small alteration in VC. These results may be explained by the underlying disease, which caused a poorly compliant lung. Pleural thickening and the resulting low chest wall compliance may also underlie the observed changes in some patients. These findings have been also confirmed by other investigators $(17,23)$.

Notwithstanding the difficulties in separating the effects of pleural effusion from those of the underlying disease, several studies $(17,18,23)$ have shown that aspiration of pleural fluid is associated with increases in static lung volume which were less than the volume of fluid removed. This observation indicates that pleural effusion caused a decrease in lung volume and a chest wall expansion in accordance with the theoretical prediction. Estenne et al (23) measured respiratory mechanics $2 \mathrm{~h}$ after removing a mean fluid volume of $1800 \mathrm{~mL}$ and observed that the mean TLC, VC and FRC increased by $640 \mathrm{~mL}, 300 \mathrm{~mL}$ 
and $460 \mathrm{~mL}$, respectively. They also demonstrated that the static pressure-volume curve of the lung was shifted upward and to the left; thus, for a given lung volume, elastic recoil pressure was lower after thoracentesis (Figure 2). Therefore, it appears that pleural effusion may alter lung compliance. Decompression of the lung with reopening of some air spaces and a decrease in the surface tension of the alveolar lining fluid layer, due to breathing at higher lung volumes, are the most plausible mechanisms that mediate the change in lung compliance. Gilmartin et al (18) studied patients $24 \mathrm{~h}$ after the removal of pleural fluid $(0.8 \mathrm{~L}$ to $2.5 \mathrm{~L}$ ) and observed that in addition to an increase in static lung volume, forced expiratory volume in $1 \mathrm{~s}$ also increased. Furthermore, they analyzed forced expiratory flow-volume curves and found that the lung emptied slightly faster in the presence of effusion. Indeed, the time constant of forced expiration derived from the slope of the expired volume-flow relationship was significantly lower before aspiration. The authors explained this finding by suggesting that pleural effusion reduced the number of functioning compliant lung units, while airway size remained inappropriately large for the reduced lung volume. This assumption is in accordance with the results of Estenne et al (23) who found that pleural effusion reduced lung compliance (Figure 2). Animal data also indicate that pleural effusion, apart from the changes in static lung volume, may also have secondary effects on lung mechanics (14).

In a landmark study, Anthonisen and Martin (16) used Xenon $^{133}$ gas distribution to study regional lung volume and ventilation in patients with small- to moderate-sized pleural effusion and no evidence of other respiratory system disease. Although regional lung volume at the base with effusion was reduced, the lung expansion at the site of effusion did not differ from that at the other side. These results suggest that, at least with small- to moderate-sized pleural effusion, the lung may be displaced by the effusion rather than compressed. It appears that the amount of pleural effusion may be a critical factor for the observed changes in the mechanics of the respiratory system.

\section{RESPIRATORY MUSCLES}

The accumulation of fluid in the pleural space may also affect the function of the respiratory muscles, primarily because of an increase in chest wall volume. The force-length relationship of respiratory muscles dictates that for a given neural activation, the pressure developed by muscles decreases with decreasing length (24). An increase in chest wall volume decreases the length of the inspiratory muscles, mainly the diaphragm, and increases the length of the expiratory muscles. It follows that with pleural effusion, all else being the same, for a given neural activation, pressure developed by the inspiratory and expiratory muscles should decrease and increase, respectively.

The effect of pleural effusion on respiratory muscle function was examined in the study of Estenne et al (23). They measured minimal pleural pressures obtained during static maximal inspiratory efforts at different volumes before and after the removal of pleural fluid, and found that for a given lung volume, pleural pressure was approximately $20 \mathrm{~cm}$ lower after thoracentesis (Figure 2). This finding indicates that either the power of the inspiratory muscles increased or their efficiency improved. The authors estimated the change in chest wall volume following fluid aspiration and observed that if minimal pleural pressure was related to chest wall volume, the pressures generated by the inspiratory muscles before and after thoracentesis fall on the

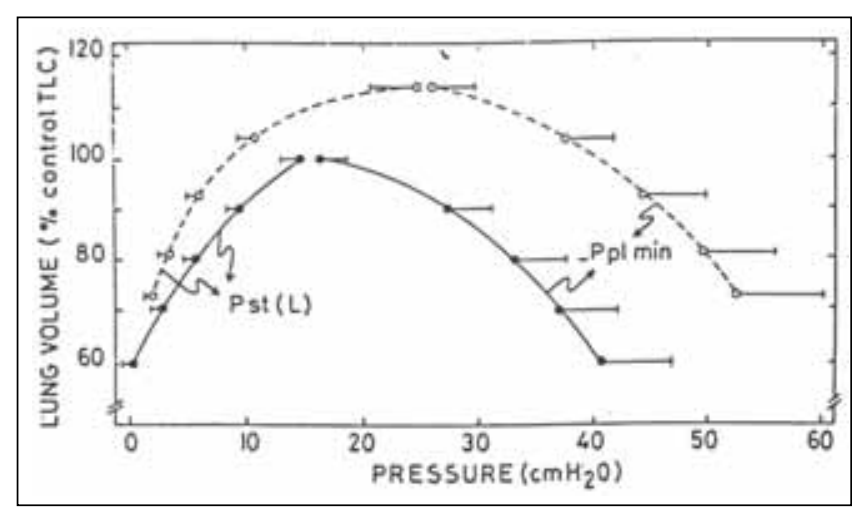

Figure 2) Pressure-volume curve of lung recoil pressure (Pst) (left) and maximal static inspiratory pleural pressure (-Ppl) (right) versus lung volume before (closed circles) and after (open circles) thoracocentesis. Lung volume is expressed as a percentage of total lung capacity (TLC) before thoracocentesis. Note that for a given lung volume, pleural pressure is approximately $20 \mathrm{~cm}$ lower (more negative) after thoracocentesis. Also, after thoracocentesis, Pst shifted upward, and this shift was associated with an increase in lung compliance. Each bar represents \pm SE. Reproduced with permission from reference 23

same curve. These results strongly suggest that by increasing the chest wall volume, pleural effusion decreases the length of the inspiratory muscles and thus, reduces their effectiveness.

The effects of pleural effusion on the expiratory muscles are not known, but according to the above results, it is reasonable to conclude that in the presence of pleural effusion, the efficiency of the expiratory muscles would probably be increased due to the increase in their length. However, this has to be proven experimentally.

\section{GAS EXCHANGE}

The gas exchange properties of the lung may be also affected by pleural effusion. Theoretically, it can be predicted that the decrease in the FRC caused by pleural effusion may reduce the lung volume at the end of expiration to near or even below the closing volume, a condition that is clearly associated with hypoxemia because it causes ventilation/perfusion mismatch (25-28). This should be further aggravated by assuming the supine position $(25-27,29)$. Finally, under certain circumstances, large pleural effusions may impede the filling of the right heart and, by decreasing the cardiac output, exaggerate the effects of ventilation/perfusion inequalities and right to left shunt on partial pressure of $\mathrm{O}_{2}$ in arterial blood $\left(\mathrm{PaO}_{2}\right)(30-32)$.

Although the above theoretical analysis predicts that pleural effusion contributes to hypoxemia (33), studies in humans have demonstrated contradictory results (34). Oxygenation has been shown improve, remain unchanged or even worsen after thoracentesis $(34,35)$. The underlying lung disease and occurrence of interstitial edema due to re-expansion of the lung after thoracentesis complicate the interpretation of these results. In an attempt to resolve this issue, Nishida et al (28) created graded, increasing bilateral pleural effusions in anesthetized pigs breathing $100 \% \mathrm{O}_{2}$. At each pleural volume, the intravascular volume varied from normal to low or normal to high to investigate the interaction between oxygenation, hemodynamics and pleural effusion. They observed that pleural effusion caused an acute decrease in $\mathrm{PaO}_{2}$, the magnitude of 

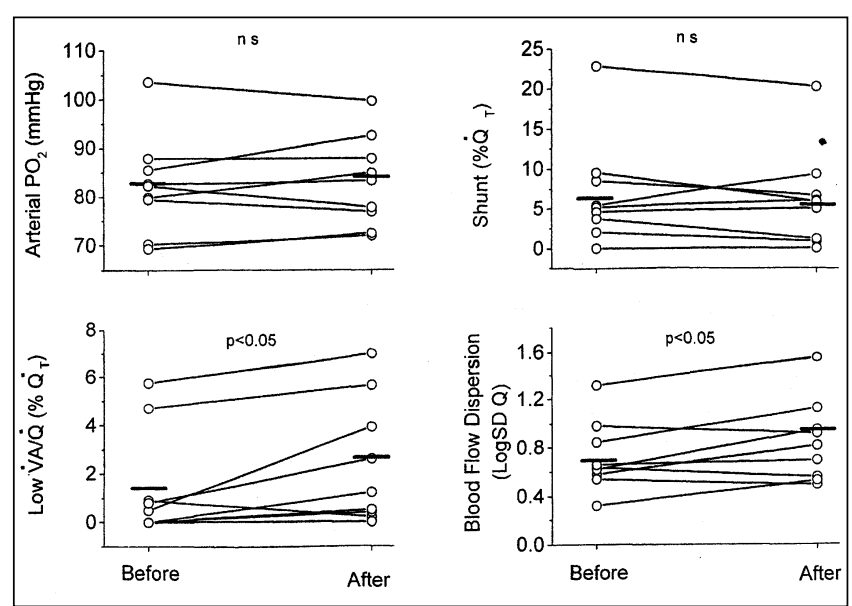

Figure 3) Individual (open circles) and mean (solid bars) values of arterial partial pressure of $\mathrm{O}_{2}\left(\mathrm{PO}_{2}\right)$, low ventilation:perfusion ratios (VA:Q), shunt and blood flow dispersion before and $30 \mathrm{~min}$ after draining pleural effusion by thoracocentesis. Reproduced with permission from reference 38. ns Not significant; $Q_{T}$ Intrapulmonary shunt

which depended on the volume of pleural effusion. The hypoxemia occurred due to intrapulmonary right to left shunt, which increased proportionally to the volume of the instilled pleural fluid. At the highest volume of pleural effusion, mixed venous $\mathrm{O}_{2}$ was reduced and this may have also contributed to the hypoxemia; particularly, in the presence of increased shunt. All these changes were reversed by aspirating the pleural fluid, without any evidence of hysteresis. Changes of intravascular volume did not appear to influence the $\mathrm{PaO}_{2}$ significantly. Although this model has several limitations, the data suggest that even moderately sized pleural effusion may be an important contributor to arterial hypoxemia, particularly in the presence of respiratory failure. It is possible that under these circumstances, removal of pleural fluid either by thoracocentesis or using negative fluid balance may have potential benefits in oxygenation.

Patients mechanically ventilated due to acute respiratory failure and coexisting pleural effusion are commonly encountered in clinical practice. Very often these patients have severe hypoxemia and a poor response to positive end-expiratory pressure. Talmor et al (36) studied these patients and observed that oxygenation and respiratory system compliance improved immediately after drainage through a chest tube. However, these results should be interpreted with caution. The risk:benefit ratio of this procedure is not well established. Furthermore, several studies in patients with acute respiratory distress syndrome have shown that mortality, the main outcome variable, is not related to the level of hypoxemia (37). It has been suggested that the improvement in oxygenation may be a cosmetic effect. Currently, insertion of a chest tube is not recommended as routine procedure in these patients. This procedure may be beneficial in selected patients with large pleural effusion and refractory hypoxemia in whom other measures to increase oxygenation have failed.

Agusti et al (38) used the multiple inert gas elimination technique in patients with pleural effusion and examined the distribution of the ventilation-perfusion ratios, as well as the effects of thoracocentesis. The results of this study showed that intrapulmonary shunt was the main mechanism underlying arterial hypoxemia, which agrees with the animal data $(28,39)$.
Withdrawing approximately $700 \mathrm{~mL}$ of pleural fluid caused a significant decrease in pleural pressure (from $3.6 \mathrm{~cm} \mathrm{H}_{2} \mathrm{O}$ to $-7.1 \mathrm{~cm} \mathrm{H}_{2} \mathrm{O}$ ) without a significant effect on $\mathrm{PaO}_{2}$, shunt and alveolar-arterial difference of the arterial partial pressure of $\mathrm{O}_{2}$ (Figure 3). A significant, although small, increase in blood flow perfusing low ventilation:ratio units was observed after thoracentesis indicating that either some degree of lung re-expansion or acute interstitial pulmonary edema occurred as a result of pleural pressure decrease. Nevertheless, despite the relatively large pleural fluid drainage, the changes in the gas exchange properties of the lung were quite small, suggesting that the effects of pleural effusion on oxygenation indexes are long-lasting, possibly due to delayed pulmonary volume re-expansion after fluid drainage $(17,40,41)$ with or without the coexistence of ex-vacuopulmonary edema (41-43).

The effect of pleural effusion on cardiac function - although beyond the scope of the present review - deserves some comments. It has been shown in dogs that large pleural effusion may compromise right heart function by inducing diastolic ineffectiveness of the right ventricle which is associated with a decrease in cardiac output (44) due to decreased venous return. This condition is similar to cardiac tamponade. This may aggravate hypoxemia, particularly in the presence of increased right to left shunt. It is of interest to note that this complication may occur when pleural pressure is approximately $4 \mathrm{~cm} \mathrm{H}_{2} \mathrm{O}$, a value that is frequently seen in patients (31). Indeed, compromised cardiac function documented by echocardiography has been reported in patients with large pleural effusion (32). Therapeutic thoracocentesis may be lifesaving in these patients by increasing cardiac output and oxygenation (23). However, we should note that removal of a relatively large volume of pleural fluid may lead to re-expansion pulmonary edema and, in some cases, to hypovolemia $(45,46)$. Re-expansion pulmonary edema may be avoided by measuring the decrease in pleural pressure during the procedure $(47,48)$. Nevertheless, although re-expansion pulmonary edema after pleural effusion removal is most likely caused by the negative pleural pressure and an associated increase in vascular permeability (48), an inflammatory mechanism may also be involved (49).

\section{CONCLUSION}

The accumulation of pleural fluid causes a restrictive ventilatory effect. Pure pleural effusion is associated with chest wall volume expansion that reduces the efficiency of the inspiratory muscles. The drainage of pleural fluid usually results in an increase in static lung volumes that is considerably less than the amount of aspirated fluid. Pleural effusion is associated with hypoxemia due to an increase in right to left shunt, an effect that, at least in humans, is not readily reversible on fluid aspiration.

\section{REFERENCES}

1. Light RW. Anatomy of the pleura. In: Light RW, ed. Pleural Diseases, Volume 1. Philadelphia: Lippincott Williams \& Wilkins, 2001:1-7

2. Fenn W. The pressure-volume diagram of the breathing mechanism. In: Boothby WM, ed. Respiratory Physiology in Aviation. Rundolph Field: USAF School of Aviation Medicine, 1954:19-27.

3. Ward ME. Respiratory mechanics. In: Murray JF, Nadel JA, eds. Textbook of Respiratory Medicine, Volume 1. Philadelphia: WB Saunders, 1994:90-138.

4. Agostoni E, D’Angelo E. Pleural liquid pressure. J Appl Physiol 1991;71:393-403. 
5. Agostoni E. Mechanics of the pleural space. Physiol Rev 1972;52:57-128.

6. Lee KF, Olak J. Anatomy and physiology of the pleural space. Chest Surg Clin N Am 1994;4:391-403.

7. Milic-Emili J, Henderson JA, Dolovich MB, Trop D, Kaneko K. Regional distribution of inspired gas in the lung. J Appl Physiol 1966;21:749-59.

8. Light RW. Physiology of the pleural space. In: Light RW, ed. Pleural Diseases, Volume 1. Philadelphia: Lippincott Williams \& Wilkins, 2001:8-20.

9. Milic-Emili J, Mead J, Turner JM, Glauser EM. Improved technique for estimating pleural pressure from esophageal balloons. J Appl Physiol 1964;19:207-11.

10. Villena V, Lopez-Encuentra A, Pozo F, De-Pablo A, Martin-Escribano P. Measurement of pleural pressure during therapeutic thoracentesis. Am J Respir Crit Care Med 2000;162:1534-8.

11. Tenney SM. Comparative mammalian respiratory control. In: Cherniak NS, Widdicombe JG, eds. The Respiratory System, Volume II. Control of Breathing. Bethesda: American Physiological Society, 1986:833-55.

12. Agostoni E. Static behavior of the respiratory system. In: Macklem PT, Mead J, eds. Handbook of Physiology, Volume III. Mechanics of Breathing. Bethesda: American Physiological Society, 1986:113-30

13. Dechman G, Sato J, Bates JH. Effect of pleural effusion on respiratory mechanics, and the influence of deep inflation, in dogs. Eur Respir J 1993;6:219-24.

14. Krell WS, Rodarte JR. Effects of acute pleural effusion on respiratory system mechanics in dogs. J Appl Physiol 1985;59:1458-63.

15. Sousa AS, Moll RJ, Pontes CF, Saldiva PH, Zin WA. Mechanical and morphometrical changes in progressive bilateral pneumothorax and pleural effusion in normal rats. Eur Respir J 1995;8:99-104.

16. Anthonisen NR, Martin RR. Regional lung function in pleural effusion. Am Rev Respir Dis 1977;116:201-7.

17. Brown NE, Zamel N, Aberman A. Changes in pulmonary mechanics and gas exchange following thoracocentesis. Chest 1978;74:540-2.

18. Gilmartin JJ, Wright AJ, Gibson GJ. Effects of pneumothorax or pleural effusion on pulmonary function. Thorax 1985;40:60-5.

19. Light RW, Stansbury DW, Brown SE. The relationship between pleural pressures and changes in pulmonary function after therapeutic thoracentesis. Am Rev Respir Dis 1986;133:658-61.

20. van Noord JA, Demedts M, Clement J, Cauberghs M, Van de Woestijne KP. Effect of rib cage and abdominal restriction on total respiratory resistance and reactance. J Appl Physiol 1986;61:1736-40

21. Lai-Fook SJ, Rodarte JR. Pleural pressure distribution and its relationship to lung volume and interstitial pressure. J Appl Physiol 1991;70:967-78.

22. Light RW, Jenkinson SG, Minh VD, George RB. Observations on pleural fluid pressures as fluid is withdrawn during thoracentesis. Am Rev Respir Dis 1980;121:799-804.

23. Estenne M, Yernault JC, De Troyer A. Mechanism of relief of dyspnea after thoracocentesis in patients with large pleural effusions. Am J Med 1983;74:813-9.

24. Younes M, Riddle W, Polacheck J. A model for the relation between respiratory neural and mechanical outputs. III. Validation. J Appl Physiol 1981;51:990-1001.

25. Craig DB, Wahba WM, Don HF, Couture JG, Becklake MR. "Closing volume" and its relationship to gas exchange in seated and supine positions. J Appl Physiol 1971;31:717-21.

26. Blair $\mathrm{E} \mathrm{H}$. The effect of change in body position on lung volume and intrapulmonary gas mixing in normal subjects. J Clin Invest 1955;34:383-98.
27. Kaneko K, Milic-Emili J, Dolovich MB, Dawson A, Bates DV. Regional distribution of ventilation and perfusion as a function of body position. J Appl Physiol 1966;21:767-77.

28. Nishida O, Arellano R, Cheng DC, DeMajo W, Kavanagh BP. Gas exchange and hemodynamics in experimental pleural effusion. Crit Care Med 1999;27:583-7.

29. Neagley SR, Zwillich CW. The effect of positional changes on oxygenation in patients with pleural effusions. Chest 1985;88:714-7.

30. Negus RA, Chachkes JS, Wrenn K. Tension hydrothorax and shock in a patient with a malignant pleural effusion. Am J Emerg Med 1990;8:205-7.

31. Kisanuki A, Shono H, Kiyonaga K, et al. Two-dimensional echocardiographic demonstration of left ventricular diastolic collapse due to compression by pleural effusion. Am Heart J 1991;122:1173-5.

32. Kaplan LM, Epstein SK, Schwartz SL, Cao QL, Pandian NG. Clinical, echocardiographic, and hemodynamic evidence of cardiac tamponade caused by large pleural effusions. Am J Respir Crit Care Med 1995;151:904-8.

33. Mattison LE, Coppage L, Alderman DF, Herlong JO, Sahn SA. Pleural effusions in the medical ICU: Prevalence, causes, and clinical implications. Chest 1997;11:1018-23.

34. Dobyns EL. Pleural effusions and hypoxemia. Crit Care Med 1999;27:472.

35. Chang SC, Shiao GM, Perng RP. Postural effect on gas exchange in patients with unilateral pleural effusions. Chest 1989;96:60-3.

36. Talmor M, Hydo L, Gershenwald JG, Barie PS. Beneficial effects of chest tube drainage of pleural effusion in acute respiratory failure refractory to positive end-expiratory pressure ventilation. Surgery 1998;123:137-43.

37. Luhr OR, Karlsson M, Thorsteinsson A, Rylander C, Frostell CG. The impact of respiratory variables on mortality in non-ARDS and ARDS patients requiring mechanical ventilation. Intensive Care Med 2000;26:508-17.

38. Agusti AG, Cardus J, Roca J, Grau JM, Xaubet A, Rodriguez-Roisin R. Ventilation-perfusion mismatch in patients with pleural effusion: Effects of thoracentesis. Am J Respir Crit Care Med 1997;156:1205-9.

39. Evans JW, Wagner PD. Limits on VA/Q distributions from analysis of experimental inert gas elimination. J Appl Physiol 1977;42:889-98.

40. Perpina M, Benlloch E, Marco V, Abad F, Nauffal D. Effect of thoracentesis on pulmonary gas exchange. Thorax 1983;38:747-50.

41. Doerschuk CM, Allard MF, Oyarzun MJ. Evaluation of reexpansion pulmonary edema following unilateral pneumothorax in rabbits and the effect of superoxide dismutase. Exp Lung Res 1990;16:355-67.

42. Trapnell DH, Thurston JG. Unilateral pulmonary oedema after pleural aspiration. Lancet 1970;1:1367-9.

43. Brandstetter RD, Cohen RP. Hypoxemia after thoracentesis. A predictable and treatable condition. JAMA 1979;242:1060-1.

44. Vaska K, Wann LS, Sagar K, Klopfenstein HS. Pleural effusion as a cause of right ventricular diastolic collapse. Circulation 1992;86:609-17.

45. Light RW. Thoracentesis and pleural biopsy. In: Light RW, ed. Pleural Diseases, Volume 1. Baltimore: Williams \& Wilkins, 1995:311-326.

46. Mahfood S, Hix WR, Aaron BL, Blaes P, Watson DC. Reexpansion pulmonary edema. Ann Thorac Surg 1988;45:340-5.

47. Nakamura M, Fujishima S, Sawafuji M, et al. Importance of interleukin-8 in the development of reexpansion lung injury in rabbits. Am J Respir Crit Care Med 2000;161:1030-6.

48. Light RW, Jenkinson SG, Minh VD, George RB. Observations on pleural fluid pressures as fluid is withdrawn during thoracentesis. Am Rev Respir Dis 1980;121:799-804.

49. Suzuki S, Tanita T, Koike K, Fujimura S. Evidence of acute inflammatory response in reexpansion pulmonary edema. Chest 1992;101:275-6. 


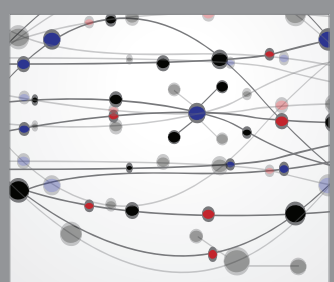

The Scientific World Journal
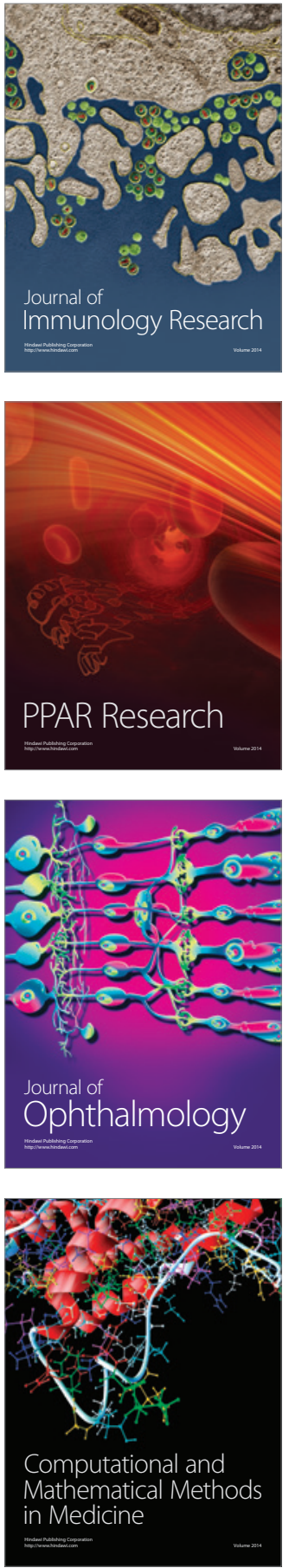

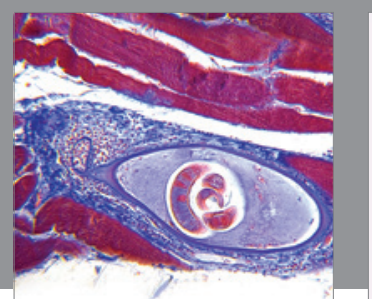

Gastroenterology Research and Practice

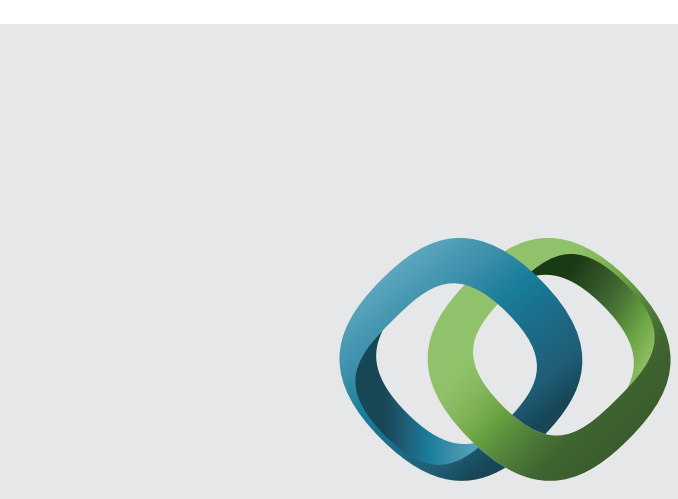

\section{Hindawi}

Submit your manuscripts at

http://www.hindawi.com
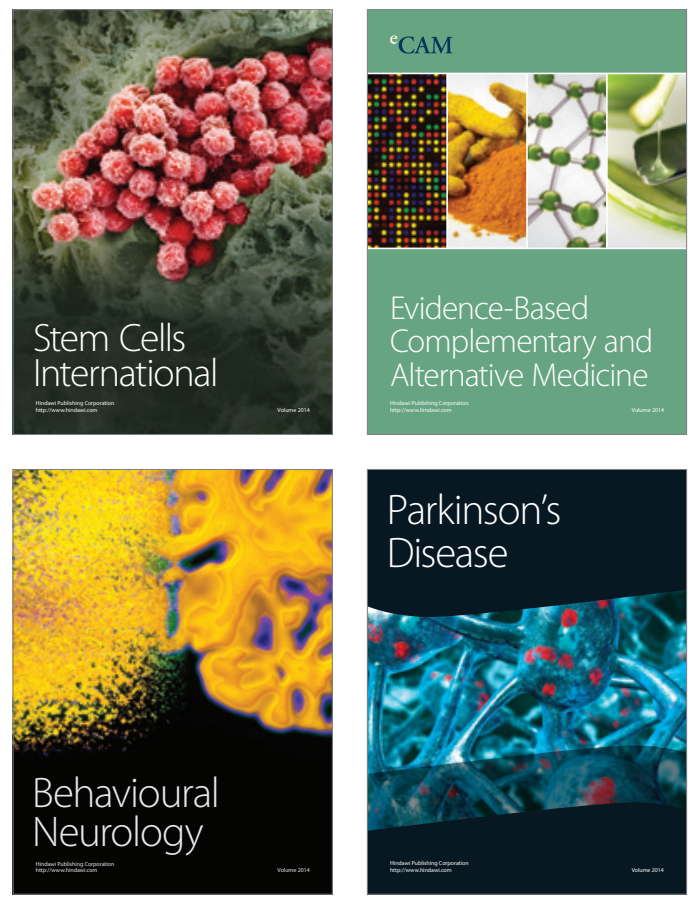
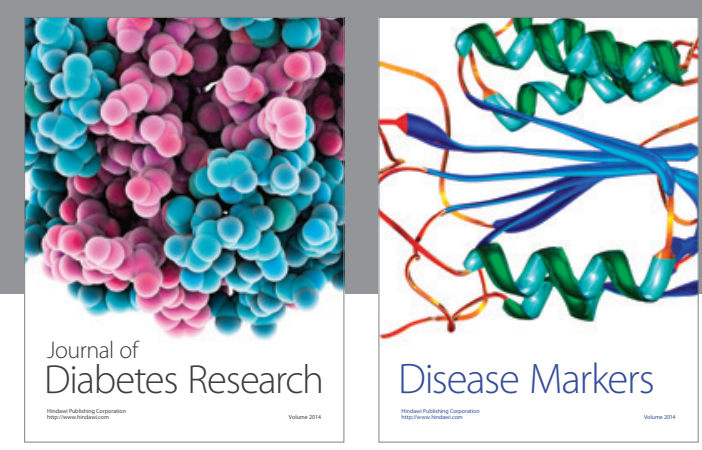

Disease Markers
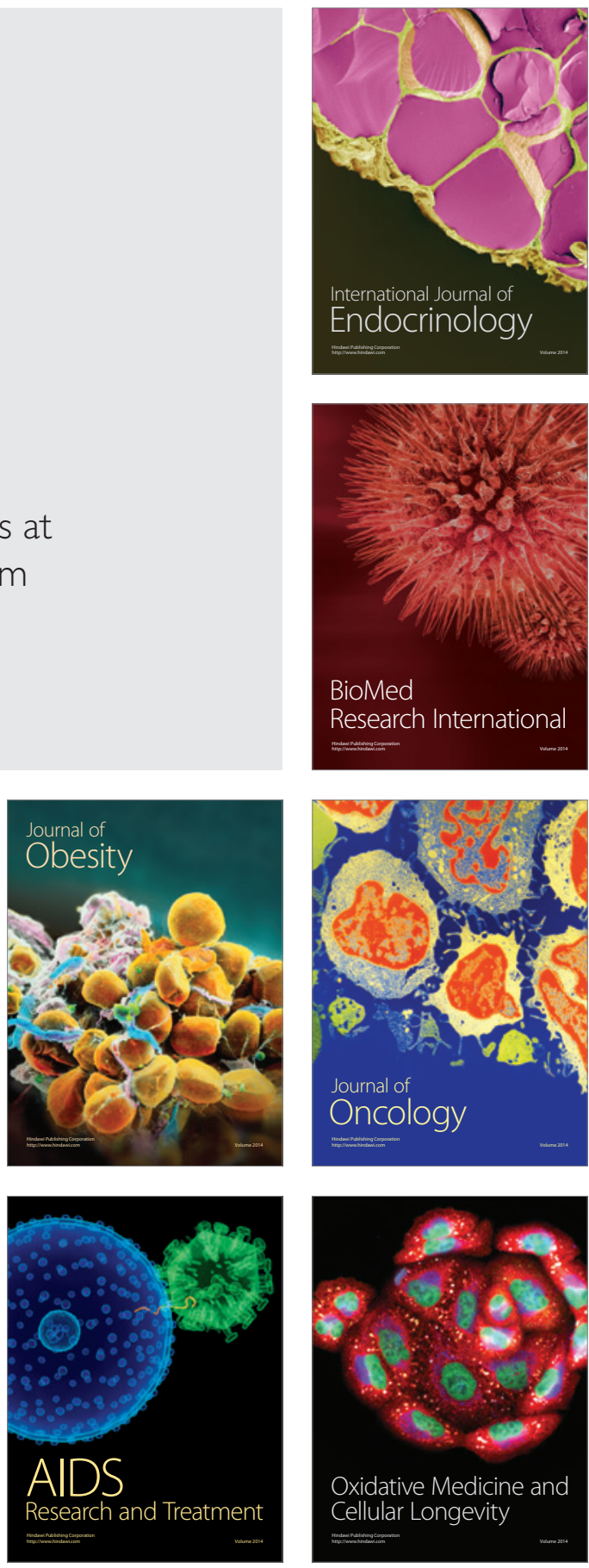